\title{
Evaluation of Radiopacity and Microhardness of Composites Submitted to Artificial Aging
}

Diogo Rodrigues Cruvinel ${ }^{\mathrm{a}}$, Lucas da Fonseca Roberti Garcia ${ }^{\mathrm{b}}$, Luciana Assirati Casemiro ${ }^{\mathrm{c}}$, Luiz Carlos Pardini ${ }^{\mathrm{d}}$ Fernanda de Carvalho Panzeri Pires-de-Souza ${ }^{\text {a* }}$

${ }^{a}$ Department of Dental Materials and Prosthodontics, School of Dentistry of Ribeirão Preto, University of São Paulo, Av do Café, s/n, Monte Alegre, 14040-904 Ribeirão Preto - SP, Brazil ${ }^{\mathrm{b}}$ Departament of Dental Materials, School of Dentistry of Piracicaba, University of Campinas, Brazil, Av. Limeira, 901, Areião, 13414-903 Piracicaba - SP, Brazil

${ }^{c}$ School of Dentistry, University of Franca, Av. Dr. Armando Salles Oliveira, 201, Parque Universitário, 14404-600 Franca - SP, Brazil

${ }^{\mathrm{d}}$ Department of Morphology, Stomatology and Physiology, School of Dentistry of Ribeirão Preto, University of São Paulo, Av do Café, s/n, Monte Alegre, 14040-904 Ribeirão Preto - SP, Brasil

Received: May 11, 2007; Revised: June 15, 2007

\begin{abstract}
The purpose of this study was to assess the radiopacity and microhardness of different types of resin-based composites (RBC-hybrid; microhybrid; flowable; cement and polyacid modified) before and after being submitted to artificial accelerated aging. Fifty specimens ( $7 \mathrm{~mm}$ in diameter and $2 \mathrm{~mm}$ thick) were fabricated, 10 for each material. The specimens were light-cured and submitted to radiopacity and microhardness tests. After obtaining initial radiopacity and microhardness values, the specimens were taken to the artificial accelerated aging, and new measurement of radiopacity and microhardness of the samples was performed. Data were submitted to statistical analysis (Student's $t$-test $-\mathrm{p}<0.05$ ). None of the materials studied showed changes in radiopacity after artificial accelerated aging. There was a significant decrease in microhardness for the microhybrid and polyacid-modified RBC's. This study suggests that radiopacity remains unaltered after materials are submitted to artificial accelerated aging. Microhardness, however, may vary due to plasticization of the aged RBC matrix.
\end{abstract}

Keywords: radiopacity, microhardness, composites, artificial aging

\section{Introduction}

Resin-based composites (RBC) have been broadly used in dentistry due to their physical characteristics, ease of handling, and especially due to their satisfactory esthetic features. Radiopacity of these materials is important enabling the detection of secondary caries, marginal defects, contour of restoration, contact with adjacent teeth, cement overhangs, and interfacial gaps ${ }^{1-7}$. It is known that highly radiopaque materials make a radiographic diagnosis more difficult ${ }^{1}$, while radiolucent materials will show up as a separate layer ${ }^{8}$. RBC radiopacity should be at least equal to that of dentin to assure that the material would not be mistaken for carious dentin'; while others suggest this radiopacity be even greater than enamel ${ }^{2,3,6,10-13}$.

The radiopacity degree can vary within the same class of material $^{2}$ and is affected by several factors. This property results from the incorporation of filler particles with into the matrix (glass and ceramic particles containing heavy metals such as aluminum, barium, strontium, and zirconium). These particles may vary greatly in their concentrations and compositions, the most important factor for radiopacity $^{2,3,12}$. For instance, RBC's intended for use in anterior teeth have filler particles that are smaller in size and lower in concentration than those intended for use in posterior teeth ${ }^{3,4}$. In addition, the material thickness ${ }^{2,3}$, the angulation of the $\mathrm{X}$ ray beam, the methodology employed for evaluation ${ }^{6,14}$, the type of $\mathrm{X}$ ray film, the age of developing and fixing solutions ${ }^{10}$, and the alteration in the power/liquid ratio ${ }^{15}$ can also have an influence.
According to the International Standardization Organization (ISO $)^{16}$, a resin material should be less radiopaque than the equivalent thickness of $99.5 \%$ pure aluminum. Some authors consider that restorative materials should have a degree of radiodensity higher than that of enamel and dentin ${ }^{2-3,6}$. Some authors ${ }^{18,19}$, supported by the stress-corrosion theory, hypothesized that the leakage of ions from RBC filler particles stored in water, was related to the corrosion of the glass particle exposed to an aqueous medium. This phenomenon, according to the authors ${ }^{19}$, occurs due to leakage of ions such as silicon, barium, strontium, and sodium into the aqueous medium. Release of such ions could break the chemical bond between the filler particle and the matrix, resulting in reduced radiopacity and diminished mechanical strength.

This investigation was based on the hypothesis that artificial accelerated aging causes degradation of the resin matrix as well as corrosion of filler particles, which leads to a reduction in the material's radiopacity and its mechanical properties. Hence, the purpose of this study was to evaluate the radiopacity and microhardness of resin material submitted to artificial accelerated aging.

\section{Methods and Materials}

This study makes use of RBC's employed in anterior and posterior teeth restorations (Table 1). These materials were chosen because, for each indicated category, they are the most frequently used materials in the dental clinic at the Ribeirao Preto Dental School. 
Table 1. Materials used in the study.

\begin{tabular}{|c|c|c|c|c|c|}
\hline Product & Brand & Components & $\begin{array}{l}\text { Particles size } \\
(\mu \mathrm{m})\end{array}$ & $\begin{array}{l}\text { Particles } \\
(\% \text { vol })\end{array}$ & Manufacturer \\
\hline Composite resin & $\mathrm{TPH}$ & $\begin{array}{l}\text { Bis-GMA, UDMA, Boron, Aluminum Silicate } \\
\text { and Silanized Barium, Silanized Pyrolytic Silica, } \\
\text { CQ, EDAB, Butylated hydroxytoluene, Mineral } \\
\text { pigments. }\end{array}$ & 800 & 79 & $\begin{array}{l}\text { Dentsply - Petrópolis, } \\
\text { Rio de Janeiro, Brazil }\end{array}$ \\
\hline Composite resin & Concept & $\begin{array}{l}\text { Bis-GMA, UDMA, Bis-EMA, Methacrylic acid } \\
\text { ester, Barium Aluminum Silicate. }\end{array}$ & 0.4 to 2 & 77.5 & $\begin{array}{l}\text { Vigodent - Rio de Janeiro, } \\
\text { Rio de Janeiro, Brazil }\end{array}$ \\
\hline Compomer & Dyract AP & $\begin{array}{l}\text { Polymerizing resins, TCB resin, Strontium fluor } \\
\text { aluminum silicate glass, Strontium fluoride, } \\
\text { Photoiniciator, Stabilizers. }\end{array}$ & & & $\begin{array}{l}\text { Dentsply - Petrópolis, } \\
\text { Rio de Janeiro, Brazil }\end{array}$ \\
\hline Resin cement & Enforce & $\begin{array}{l}\text { Base paste: TEGDMA, Boron glass, Alumi- } \\
\text { num Silicate and Silanized Barium, Silanized } \\
\text { Pyrolytic Silica, CQ, EDAB, BHT, Mineral } \\
\text { Pigments, DHEPT. } \\
\text { Catalyzing Paste: Titanium Dioxide, Silanized } \\
\text { Pyrolytic Silica, Mineral Pigment, Bis-GMA, } \\
\text { BHT, EDAB TEGDMA, Benzoyl peroxide. }\end{array}$ & & & $\begin{array}{l}\text { Dentsply - Petrópolis, } \\
\text { Rio de Janeiro, Brazil }\end{array}$ \\
\hline Flow resin & Tetric Flow & $\begin{array}{l}\text { Bis-GMA, UDMA, TEGDMA, Barium glass, } \\
\text { Ytterbium trifluoride, Barium fluor aluminum } \\
\text { silicate glass, silicon dioxide and mixed sphe- } \\
\text { roidal oxides. }\end{array}$ & $0.04-3.0$ & 39.7 & $\begin{array}{l}\text { Ivoclar Vivadent - São Paulo, } \\
\text { São Paulo, Brazil. }\end{array}$ \\
\hline
\end{tabular}

The specimens ( $2 \mathrm{~mm}$ in thickness and $7 \mathrm{~mm}$ in diameter) were obtained using a Teflon matrix, with a central axis and a sliding portion over that. In order to assure compacting and to allow the excess resin material to flow, a glass plate was placed over the material that was inserted into the matrix. This technique was chosen specifically because it eliminates the presence of air from the RBC surface, which improves conversion degree. Polymerization was performed using a halogen lamp for 40 seconds (Ultralux Electronic, Dabi Atlante, Ribeirão Preto, São Paulo, Brazil, 400-500 nm, 450 mW.cm-2).

Fifty specimens (10 for each type of material) were fabricated. After removing the specimens from the matrix, they were polished using sandpaper discs following a descending order of granulation granulometry (Sof-Lex, 3M do Brasil, Sumaré, São Paulo, Brazil). To prevent overheating and surface change, polishing was done in a wet environment and using soft alternate movements. After completing the polishing, with the aid of a digital caliper, it was verified that the specimen thickness was $2 \mathrm{~mm}$. All specimens were coded and stored in individual containers with $100 \%$ humidity. The specimens were kept in a dark environment until the moment to be placed in the Accelerated Aging System (Comexim Matérias Primas Ltda, São Paulo, Brasil). The specimens were then randomly divided into two groups $(\mathrm{n}=25)$, with five samples for each studied RBC (Table 1), which complies with ASTM Standards G154-00A. One group was evaluated in terms of radiopacity and the other was submitted to a microhardness test.

To analyze radiopacity, each group of five-specimen group was radiographed using a $70 \mathrm{KVp} \mathrm{X}$ ray apparatus (Spectro 70X, Dabi Atlante, Ribeirão Preto, São Paulo, Brazil), on top of a periapical radiographic film (Kodak Insight, tipo E, Manaus, Amazonas, Brazil). The exposure time was 0.30 second and the focus-film distance was $20 \mathrm{~cm}$. Films were manually developed in a darkroom following the time/temperature recommendations of the manufacturer (Kodak, Manaus, Amazonas, Brazil).
A $99.5 \%$ pure aluminum step wedge with eight different degrees of thickness (2 to $16 \mathrm{~mm}$ ) was placed on top of the radiographic film. This was meant to control the quality of radiography and film development. Specimens were placed clockwise, following a randomly pre-established sequence below the aluminum step wedge. Metal letters and numbers codified the category of material, and the repetition number (Figure 1).

Five radiographs were obtained. Optical density (Photodensitometer Vitoreen - Model 7-424, USA) of the samples was measured in triplicate. Optical density for each thickness of the aluminum step wedge was also measured. Radiopacity of the materials was calculated in relation to the optical density of the aluminum step wedge $(2 \mathrm{~mm})$ using the formula below ${ }^{20}$ :

$$
\mathrm{R}=\mathrm{OD}(\mathrm{mr}) \times 100 / \mathrm{OD}(\mathrm{Al})
$$

where: $\mathrm{R}=$ radiopacity of the restorative material sample $(2 \mathrm{~mm})$; $\mathrm{OD}(\mathrm{mr})=$ optical density of the restorative material sample $(2 \mathrm{~mm})$; and $\mathrm{OD}(\mathrm{Al})=$ optical density of aluminum $(2 \mathrm{~mm})$.

Microhardness of sample surfaces was measured (HMV, Shimatzu, Kyoto, Japan) at three different points and was represented by the mean value of Vickers surface microhardness.

The fifty specimens were submitted to accelerated artificial aging (C-UV, Comexim Matérias Primas Ltda, São Paulo, São Paulo, Brazil), in which independent UV light and water condensation cycles took place continually and automatically. The working program was fixed to 4 hours of exposure to UV-B at $50{ }^{\circ} \mathrm{C}$ and 4 hours of water condensation at $50{ }^{\circ} \mathrm{C}$, with a maximum aging time of 384 hours $^{21}$. After artificial accelerated aging, the specimens were radiographed again to measure the optical density in the same way as done initially, and then submitted to the microhardness test. The mean values of optical density for the step wedge and for samples, before and after artificial accelerated aging, were analyzed by Student's $t$ test $-95 \%$ significance. The same occurred with the data concerning surface microhardness before and after accelerated aging. 


\section{Results and Discussion}

\subsection{Radiopacity}

The quality control of making and developing the radiographic images may be confirmed in Figure 2, which represent a standardization of the method since they show similar behavior. The statistical analysis for optical density values obtained for the step wedge did not show any statistically significant differences.

Comparing the samples before and after artificial accelerated aging, statistical analysis showed no significant difference between the materials in terms of radiopacity (Table 2 ).

The present study was based on the hypothesis that the clinical use of a RBC might make its radiographic image less visible, which could lead to an incorrect diagnosis of caries. Furthermore, the loss of components responsible for radiopacity could reduce the material's properties, such as microhardness.

Radiopacity is essential to any type of restorative material. ISO norm ${ }^{16}$ states that the minimum radiopacity of a restorative material

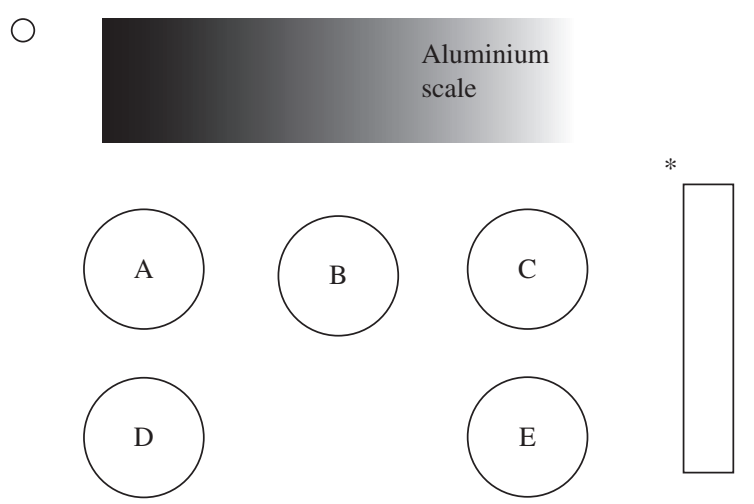

Figure 1. Scheme of the radiographic procedure. Sequence: A) TPH; B) Concept; C) Enforce; D) Tetric Flow; E) Dyract; and * Metal letters and numbers.

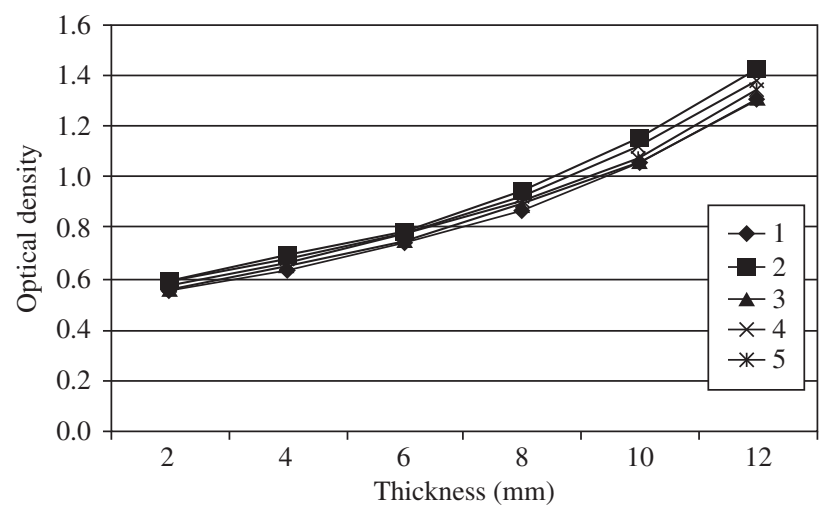

Figure 2. Optical density of the aluminum step wedge before accelerated aging measured at five radiographs. should be equal or greater than that of the $2 \mathrm{~mm}$-thick aluminum step wedge. Results showed that all the RBC's studied, before being submitted to accelerated aging, complied with this norm. After accelerated aging, however, there was a tendency toward reduction in radiopacity but with no statistical significance. The materials maintained radiopacity above that of the aluminum step wedge (1 mm).

Radiopacity of restorative materials is due to the presence of filler particles composed of glass and ceramic particles containing heavy metals, such as barium (Ba), strontium $(\mathrm{Sr})$ and zirconium $(\mathrm{Zr})^{23}$. These glassy materials also have a refraction index of 1.5 , which equals that of the resin. Barium ceramics are the most commonly used particles. Although they promote radiopacity, these fillers are not as inert in water as is quartz ${ }^{24}$.

Many studies have emphasized the need for high radiopacity of flowable RBC when used in posterior teeth restorations ${ }^{25-27}$. In the present study, microhybrid RBC was the resin that showed the highest radiopacity (Table 2), which remained the same after aging. The cement and hybrid RBC's also showed high radiopacity before aging. However, after aging there was a small, non-statistically significant, reduction of physical and mechanical properties in both materials.

The incorporation of filler particles with the resin matrix improves the properties of that component if the filler is strongly bonded to the matrix ${ }^{28-30}$. This allows the polymer, which is more flexible, to transfer stress tension to the particles, which are more rigid. However, if that bond is not strong the filler may weaken the material. Authors ${ }^{30}$ suggest that resin-particles interfaces can act as sites for crack initiation and propagation in regions where tensile stress arise. Hence, silanization of filler particles in matrix resin is essential to the success of a RBC, and if appropriately used, it enhances the physical and mechanical properties of the material ${ }^{31}$.

The reinforcing effect of glass fillers only remains effective as long as the particulate filler phase and resin matrix phase are bonded together. If a deterioration of the silane coupling occurs with accelerated aging, it reduces the retention of filler particles ${ }^{32}$. Such degradation of the matrix/silane/filler union may be caused by water sorption that penetrates into the filler/resin interface and makes silane hydrolysis easier. This, in turn, may cause a loss of filler particles and, consequently, lower microhardness ${ }^{33}$.

\subsection{Microhardness}

Table 3 lists the differences between the mean initial and final Vickers microhardness values. Statistical analysis revealed statistically significant differences in relation microhybrid and polyacidmodified RBCs. No statistically significant difference was found for the other materials.

The results for microhardness showed a statistical significance only for microhybrid and polyacid-modified RBCs. Microhybrid RBC, which has medium-sized particles of $0.4 \mu \mathrm{m}$ and $77.5 \%$ filler particles by weight, showed a higher initial microhardness value. Nevertheless, after artificial accelerated aging, there was a reduction in microhardness of approximately $56 \%$ (Table 3). Hybrid RBC, however, although containing $79 \%$ filler particles by weight, showed a $12 \%$ reduction in microhardness. Hence, this study is in agreement with the findings by Schulze et al. ${ }^{34}$, which reported that high levels

Table 2. Radiopacity average values and standard deviation before and after artificial accelerated aging.

\begin{tabular}{ccccc}
\hline Accelerated aging & \multicolumn{3}{c}{ Materials } \\
\cline { 2 - 5 } & TPH & Concept & Enforce & Tetric flow \\
\hline Before & $1.28(0.06)^{\mathrm{a}}$ & $1.71(0.05)^{\mathrm{a}}$ & $1.56(0.18)^{\mathrm{a}}$ & $1.55(0.17)^{\mathrm{a}}$ \\
After & $1.26(0.10)^{\mathrm{a}}$ & $1.65(0.13)^{\mathrm{a}}$ & $1.54(0.25)^{\mathrm{a}}$ & $1.52(0.13)^{\mathrm{a}}$ \\
\hline
\end{tabular}

Different letters in the column indicate statistically significant differences (Student's $t$ test $-\mathrm{p}<0.05$ ). 
Table 3. Means (standard deviation) of initial and final Vickers microhardness values, and the differences between the sample means.

\begin{tabular}{llcccc}
\hline & TPH & Concept & Enforce & Tetric flow & Dyract \\
\hline Initial microhardness & $89.2(3.0)^{\mathrm{a}}$ & $111.9(15.1)^{\mathrm{a}}$ & $62.2(7.7)^{\mathrm{a}}$ & $44.1(5.6)^{\mathrm{a}}$ & $78.4(5.8)^{\mathrm{a}}$ \\
Final microhardness & $78.8(19.2)^{\mathrm{a}}$ & $48.4(5.9)^{\mathrm{b}}$ & $64.8(13.4)^{\mathrm{a}}$ & $45.7(6.1)^{\mathrm{a}}$ & $63.7(5.6)^{\mathrm{b}}$ \\
\hline
\end{tabular}

Different letters in the column indicate statistically significant differences (Student's $t$ test $-\mathrm{p}<0.05$ ).

of hardness are not related exclusively with the particle content in a RBC. The composition and the distribution of the filler sizes may be more important factors for this property. The level of conversion is another factor that interferes in material hardness; however, it was not part of this study's design ${ }^{35}$.

Studies report a significant decrease in mechanical properties caused by hydrolysis of resin matrix ${ }^{36}$. The storage solution is usually water that can infiltrate and decrease the mechanical properties of the polymer matrix, by swelling and reducing the frictional forces between the polymer chains, a process known as 'plasticization' ${ }^{37-40}$. Similar results were obtained with artificial saliva solutions $\mathrm{s}^{41,42}$.

For polyacid-modified RBC, the reduction was of about $18 \%$. Contrary to highly filled restorative hybrid-type composite resins, polyacid-modified composite resins generally contain more organic matrix and thus may be more susceptible to water absorption and a subsequent surface disintegration in an aqueous environment ${ }^{43}$. Cattani-Lorente et al. ${ }^{44}$ investigated the affect of the water sorption upon the mechanical characteristics of a resin modified glass ionomer cement and polyacid-modified RBC. In contact with water, both materials became more plastic than dry samples and underwent a greater deformation before fracturing. Sorbed water behaves as a plasticizer for the materials with subsequent softening of the specimens caused by a hydrolytic irreversible disintegration of the matrix and/or the filler-resin-interface ${ }^{45}$.

The results of the present study indicate that despite the degradation of the polymeric matrix caused by silane hydrolysis, the consequent loss of filler particles is not sufficient to substantially change radiopacity. New studies are called for in order to verify if longer periods of aging change these results.

\section{Conclusion}

The results allow for the conclusion that in terms of radiopacity, there was no significant change when materials were submitted to 384 hours of artificial accelerated aging. In relation to microhardness, behavior after artificial aging depends on the type of restorative material, size and distribution of the filler particles present within the RBC and material's susceptibility to water sorption.

\section{References}

1. Espelid I, Tveit AB, Erickson RL, Keck SC, Glasspoole EA. Radiopacity of restorations and detection of secondary caries. Dental Materials. 1991; 7(2):114-117.

2. Hara AT, Serra MC, Haiter-Neto F, Rodrigues Junior AL. Radiopacity of esthetic restorative materials compared with human tooth structure. American Journal of Dentistry. 2001; 14(6):383-386.

3. Hara AT, Serra MC, Rodrigues Junior AL. Radiopacity of glass-ionomer/composite resin hybrid materials. Brazilian Dental Journal. 2001; 12(2):85-89.

4. Rubo MH, el-Mowafy O. Radiopacity of dual-cured and chemical-cured resin-based cements. International Journal of Prosthodontics. 1998; 11(1):70-74.

5. Toyooka H, Taira M, Wakasa K, Yamaki M, Fujita M, Wada T. Radiopacity of 12 visible-light-cured dental composite resins. Journal of Oral Rehabilitation. 1993; 20(6):615-622.
6. Turgut MD, Attar N, Onen A. Radiopacity of direct esthetic restorative materials. Operative Dentistry. 2003; 28(5):508-514.

7. Tveit AB, Espelid I. Radiographic diagnosis of caries and marginal defects in connection with radiopaque composite fillings. Dental Materials. 1986; 2(4):159-162.

8. Akerboom HB, Kreulen CM, van Amerongen WE, Mol A. Radiopacity of posterior composite resins, composite resin luting cements, and glass ionomer lining cements. Journal of Prosthetic Dentistry. 1993; 70(4):351-355.

9. Mjor IA. Human coronal dentine: structure and reactions. Oral Surgery Oral Medicine Oral Pathology. 1972; 33(5):810-823.

10. el-Mowafy OM, Benmergui C. Radiopacity of resin-based inlay luting cements. Operative Dentistry. 1994; 19(1):11-15.

11. Shah PM, Chong BS, Sidhu SK, Ford TR. Radiopacity of potential rootend filling materials. Oral Surgery Oral Medicine Oral Pathology Oral Radiology Endodontics. 1996; 81(4):476-479.

12. Sidhu SK, Shah PM, Chong BS, Pitt Ford TR. Radiopacity of resin-modified glass-ionomer restorative cements. Quintessence International. 1996; 27(9):639-643.

13. Van Dijken JW, Wing KR, Ruyter IE. An evaluation of the radiopacity of composite restorative materials used in Class I and Class II cavities. Acta Odontologica Scandinavica. 1989; 47(6):401-407.

14. Cook WD. An investigation of the radiopacity of composite restorative materials. Australian Dental Journal. 1981; 26(2):105-112.

15. Fonseca RB, Branco CA, Soares PV, Correr-Sobrinho L, Haiter-Neto F, Fernandes-Neto AJ, Soares CJ. Radiodensity of base, liner and luting dental materials. Clinical Oral Investigation. 2006; 10(2):114-118.

16. ISO-Standards. ISO 4049 Polymer-based filling, restorative and luting materials Technical Committee 106 - Dentistry Geneve: International Organization for Standardization. 2000. p. 1-27.

17. The desirability of using radiopaque plastics in dentistry: a status report Council on Dental Materials Instruments and Equipments. Journal of the American Dental Association. 1981; 102(3):347-349.

18. Soderholm KJ. Leaking of fillers in dental composites. Journal of Dental Research. 1983; 62(2):126-130.

19. Soderholm KJ, Zigan M, Ragan M, Fischlschweiger W, Bergman M. Hydrolytic degradation of dental composites. Journal of Dental Research. 1984; 63(10):1248-1254.

20. Darvell BW. Radiography In: Darvell BW (ed). Materials Science for Dentistry 6th edition Hong Kong. 2002. p. 489-505.

21. ASTM-Standards. ASTM STANDARDS G154-00A Standard practice for operating fluorescent light apparatus for UV exposure of nonmettalic materials. Pennsylvania: Annual Book of ASTM Standards. 2006. p. 646-654.

22. ISO-Standards. ISO - 4582 Plastics -- Determination of changes in color and variations in properties after exposure to daylight under glass, natural weathering or laboratory light sources Geneva: International Organization for Standardization. 2006. p. 1-14.

23. Zhou M, Drummond JL, Hanley L. Barium and strontium leaching from aged glass particle/resin matrix dental composites. Dental Materials. 2005; 21(2):145-155.

24. Aoyagi Y, Takahashi H, Iwasaki N, Honda E, Kurabayashi T. Radiopacity of experimental composite resins containing radiopaque materials. Dental Materials J. 2005; 24(3):315-320.

25. Attar N, Tam LE, McComb D. Flow, strength, stiffness and radiopacity of flowable resin composites. Journal of Canadian Dental Association. 2003; 69(8):516-521. 
26. Bouschlicher MR, Cobb DS, Boyer DB. Radiopacity of compomers, flowable and conventional resin composites for posterior restorations. Operative Dentistry. 1999; 24(1):20-25

27. Murchison DF, Charlton DG, Moore WS. Comparative radiopacity of flowable resin composites. Quintessence International. 1999; 30(3):179-184.

28. Debnath S, Ranade R, Wunder SL, McCool J, Boberick K, Baran G. Interface effects on mechanical properties of particle-reinforced composites. Dental Materials. 2004; 20(7):677-686.

29. Debnath S, Wunder SL, McCool JI, Baran GR. Silane treatment ef fects on glass/resin interfacial shear strengths. Dental Materials. 2003; 19(5):441-448.

30. Ikejima I, Nomoto R, McCabe JF. Shear punch strength and flexural strength of model composites with varying filler volume fraction, particle size and silanation. Dental Materials. 2003; 19(3):206-211.

31. Carrilho MR, Carvalho RM, Tay FR, Pashley DH. Effects of storage media on mechanical properties of adhesive systems. American Journal of Dentistry. 2004; 17(2):104-108.

32. Kolbeck C, Rosentritt M, Lang R, Handel G. Discoloration of facing and restorative composites by UV-irradiation and staining food Dental Materials. 2006; 22(1):63-68.

33. Musanje L, Darvell BW. Aspects of water sorption from the air, water and artificial saliva in resin composite restorative materials Dental Materials. 2003; 19(5):414-422.

34. Schulze KA, Marshall SJ, Gansky SA, Marshall GW. Color stability and hardness in dental composites after accelerated aging Dental Materials. 2003; 19(7):612-619.

35. Ferracane JL, Condon JR. Post-cure heat treatments for composites: properties and fractography Dental Materials. 1992; 8(5):290-295.

36. De Munck J, Van Meerbeek B, Yoshida Y, Inoue S, Vargas M, Suzuki K, Lambrechts P, Vanherle G. Four-year water degradation of totaletch adhesives bonded to dentin. Journal of Dental Research. 2003; 82(2):136-40.
37. Ferracane JL, Berge HX, Condon JR. In vitro aging of dental composites in water--effect of degree of conversion, filler volume, and filler/matrix coupling Journal of Biomedical Material Research. 1998; 42(3):465-472.

38. Santerre JP, Shajii L, Leung BW. Relation of dental composite formulations to their degradation and the release of hydrolyzed polymeric-resinderived products Critical reviews in oral biology and medicine. 2001; 12(2):136-151.

39. Malacarne J, Carvalho RM, de Goes MF, Svizero N, Pashley DH, Tay FR, Yiu CK, Carrilho MR. Water sorption/solubility of dental adhesive resins. Dental Material. 2006; 22(10):973-80.

40. Santerre JP, Shajii L, Leung BW. Relation of dental composite formulations to their degradation and the release of hydrolyzed polymeric-resinderived products. Critical Reviews in Oral Biology, Medicine. 2001; 12(2):136-51.

41. De Munck J, Van Landuyt K, Peumans M, Poitevin A, Lambrechts P, Braem M, Van Meerbeek B. A critical review of the durability of adhesion to tooth tissue: methods and results Journal of Dental Research. 2005 84(2):118-132.

42. Kitasako Y, Burrow MF, Nikaido T, Tagami J. The influence of storage solution on dentin bond durability of resin cement Dental Materials. 2000; 16(1):1-6.

43. Millerding P, Ahlgren F, Wennerberg A, Örtengren U, Karlsson S. Microhardness and surface topography of a composite resin cement after water storage, International Journal Prosthodontics. 1998; 11(1):21-26.

44. Cattani-Lorente MA, Dupuis V, Payan J, Moya F, Meyer JM. Effect of water on the physical properties of resinmodified glass ionomer cements. Dental Materials. 1999; 15(1):71-8.

45. Munack J, Haubert H, Dogan S, Geurtsen W. Effects of various storage media on surface hardness and structure of four polyacid-modified composite resins ("compomers"). Clinical Oral Investigation. 2001; 5(4):254-9. 
